\title{
A comprehensive experimental evaluation of asphaltene dispersants for injection under reservoir conditions
}

\author{
Hamed Firoozinia ${ }^{1} \cdot K_{\text {Kazem Fouladi Hossein Abad }}{ }^{1}$ Akbar Varamesh $^{1}$
}

Received: 27 January 2015/Published online: 1 March 2016

(C) The Author(s) 2016. This article is published with open access at Springerlink.com

\begin{abstract}
As the efficiency of dispersants with different origins is questionable for each typical oil sample, the present study provides a reproducible and reliable method for screening asphaltene dispersants for a typical asphaltenic crude oil. Four different asphaltene dispersants (polyisobutylene succinimide, polyisobutylene succinic ester, nonylphenol-formaldehyde resin modified by polyamines, and rapeseed oil amide) were prepared and their performance on two oils from an Iranian field under laboratory and reservoir conditions was studied. A thorough analysis including ash content and SARA tests was performed on the solid asphaltene particles to characterize the nature of deposits. Then a highly efficient carrier fluid, which is crucial when injecting dispersant into the wells, was selected from a variety of chemicals by comparing their solubility. In the next step, using an optical microscope, a viscometer, and a Turbiscan, the screening of dispersants under laboratory conditions was done on a mixture of dead oil and dispersant to evaluate the onset of asphaltene precipitation and its stability when titrating by a precipitant. Finally, two different mixtures of the efficient dispersants, live oil, and carrier fluid were used with the solid detection system (SDS) and the filtration method to examine their effects on the onset pressure of asphaltene precipitation and the asphaltene content of the crude oil under reservoir conditions. The results show that the combination of experimental methods used in this work
\end{abstract}

Hamed Firoozinia

firooziniah@ripi.ir

1 Research Institute of Petroleum Industry, Tehran 1485733111, Iran

Edited by Yan-Hua Sun could be consistently applied to screening asphaltene dispersants. Among the four different dispersants applied here, the dispersant based on nonylphenol-formaldehyde resin modified by polyamines showed the best performance on the available live oils. This chemical modified the onset pressure of asphaltene precipitation of light oil from 4300 psi to about $3600 \mathrm{psi}$ and decreased the precipitated asphaltene of heavy oil by about $30 \%$.

Keywords Asphaltene - Dispersant - Solvent - Onset point $\cdot$ Precipitation $\cdot$ Deposition

\section{Introduction}

Deposition of solids, organic (wax and asphaltene) and inorganic (scales, sand, and corrosion products), can clog production flow paths, reducing hydrocarbon production (Leontaritis 1996; Cosultchi et al. 2001; Thawer et al. 1989). Among the typical flow assurance problems, asphaltene precipitation and deposition is held to be the most complicated one. The reason behind this distinction is the intricate nature of asphaltenes with respect to other hydrocarbon compounds (Turta et al. 1997).

Asphaltenes are the heaviest and most polar constituent in crude oil. They have a wide range of molecular weights owing to various combinations of aliphatic chains and polycondensed aromatic rings in their structures (Kawanaka et al. 1991; Zendehboudi et al. 2013). Although the mechanisms of asphaltene precipitation and deposition and its characteristics are well illustrated in the literature, accurate prediction of asphaltene deposits and effective remedies have remained challenging due to the complexities (Zendehboudi et al. 2014). 
One way of preventing asphaltene precipitation and deposition is to use predictive models to design an efficient operation processes. Several models have been reported for prediction of asphaltene precipitation behavior (Hirscberg et al. 1984; Speight et al. 1985; Mansoori 1997; Junior et al. 2006). Despite the fact that the asphaltene precipitation and deposition is a nonlinear process, some of these predictive models are only valid within particular process conditions and rely on linear identification models (Zendehboudi et al. 2014). Recently, an artificial neural network has been considered as a strong technique to accurately model the highly nonlinear systems. Miri et al. (2014), for instance, used an optimization approach in order to determine the asphaltene surface deposition, entrainment, and plugging based on experimental data.

In addition to predictive tools, mechanical and biological methods can also be used to control asphaltene deposition under limited conditions. Mechanical methods are not applicable within the formation, especially near the wellbore area where maximum deposition occurs. Biological methods may need months or years to degrade noticeable amount of asphaltenes (Mansoori 2010).

Besides the mentioned methods, addition of chemicals such as dispersants is one of the most efficient techniques for mitigating asphaltene precipitation and deposition which is the subject of this paper.

Asphaltene dispersants (ADs) are a class of chemical additives which can be used to control asphaltene deposition (Oschmann 2002). They have been successfully applied to inhibiting and removing asphaltene deposits as a formation squeeze, batch, or continuous injection (Manek 1995).

ADs reduce the size of flocculated asphaltenes and keep them in suspension (Marques et al. 2004; Smith et al. 2008). In general, $\mathrm{ADs}$ are composed of a polar group (due to the presence of hetero-atoms like oxygen, nitrogen, phosphorous) which attach to the surface of asphaltenes and an alkyl group which prevents the adhesion of asphaltene nanoaggregates. These two groups interact with aggregated asphaltenes and with the help of a long alkyl tail they are able to change the polarity of the outer surface of aggregates. Therefore, the aggregates will have properties closer to those of crude oil and will remain dispersible in the crude oil (Barcenas et al. 2008; Ferrara 1995). An important feature of ADs is that an increase in the dosage of an AD above its optimum concentration causes the self-association of $\mathrm{AD}$ surfactant molecules resulting in an adverse effect on asphaltene aggregation (Barcenas et al. 2008).

ADs may have different results when using live and dead oils. That depends on the presence of resins in the solution for optimum performance of these chemicals. In fact, the tests conducted on dead oil or a solution containing asphaltenes redissolved in an aromatic solvent can be useful for primary screening of ADs (Borchardt 1989;
Bouts et al. 1995; Manek 1995; Takhar 1997; Oschmann 2002). The secondary, more reliable, screening is done under reservoir conditions to meet plausible influence of thermodynamic conditions on dispersant performance.

In the present work, the live and dead oil samples of two types of crude oil (oil A and oil B) were prepared and the effects of four dispersants on their asphaltene behavior were studied. The approach is to investigate the efficiency of these chemicals by considering the onset of asphaltene precipitation and its stability by thermodynamic conditions. The onsets of asphaltene precipitation are determined by a viscometer, an optical microscope, a solid detection system (SDS), and a filtration method. The stability of asphaltenes is measured by the Turbiscan. The onset points detected with each method differ from each other as the asphaltene aggregates should have reached a certain size in order to be recognized by these techniques. However, the aim of these experiments is to find to what extent the applied dispersant can delay the formation of asphaltene aggregates.

Since the injection of dispersant directly into the PVT cell is almost impossible due to the small quantity of dispersant needed, a set of experiments was also designed to select a proper carrier fluid. The effect of the carrier fluid on the onset of precipitation was investigated under atmospheric conditions to ensure that the correct value of onset point was obtained. Admittedly, in the field, the carrier fluid was able to remove the deposited asphaltenes from the interior tubing wall while the dispersant within the solution slowed the growth and formation of asphaltene flocculation.

Some dispersants may decompose at high temperatures, therefore, tests under reservoir conditions such as SDS and filtration methods can be considered as promising tools for choosing the best dispersant before injecting into a well.

\section{Experimental}

\subsection{Experimental materials}

The dead oil and live oil samples were obtained from two different formations of the Arvandan field, and the asphaltenes and deposited solids were sampled from the pipelines from the same field. The live oil samples were taken with a bottom-hole sampler (Ruska) to be wholly representative of the original, in-place fluids and their properties are summarized in Table 1.

The dispersants (DB, DF, DP, and DR) were synthesized by our group in the Research Institute of Petroleum Industry (RIPI). Table 2 shows the characteristics of produced dispersants. Research-grade $n$-heptane, toluene, and xylene were provided by Merck. Sol-100 and Sol-200 solvents were from RIPI. Gas oil and kerosene were provided by NIOPDC. 
Table 1 Characteristics of Oil A and Oil B

\begin{tabular}{|c|c|c|c|c|}
\hline Oil sample & Dead oil A & Reservoir oil A & Dead oil B & Reservoir oil B \\
\hline \multicolumn{5}{|l|}{ Component, mol \% } \\
\hline $\mathrm{H}_{2} \mathrm{~S}$ & 0 & 0.03 & 0 & 0.13 \\
\hline $\mathrm{N}_{2}$ & 0 & 0.10 & 0 & 0.30 \\
\hline $\mathrm{CO}_{2}$ & 0 & 2.02 & 0 & 3.33 \\
\hline $\mathrm{C}_{1}$ & 0 & 43.59 & 0 & 26.50 \\
\hline $\mathrm{C}_{2}$ & 0.07 & 9.47 & 0.1 & 7.37 \\
\hline $\mathrm{C}_{3}$ & 0.45 & 5.49 & 0.49 & 4.51 \\
\hline$i-\mathrm{C}_{4}$ & 0.97 & 1.47 & 0.68 & 0.60 \\
\hline$n-\mathrm{C}_{4}$ & 4.63 & 3.06 & 1.47 & 2.03 \\
\hline$i-\mathrm{C}_{5}$ & 2.89 & 1.32 & 1.57 & 2.49 \\
\hline$n-\mathrm{C}_{5}$ & 3.39 & 1.53 & 1.65 & 2.96 \\
\hline $\mathrm{C}_{6}$ & 13.81 & 5.19 & 19.69 & 7.56 \\
\hline $\mathrm{C}_{7}$ & 10.5 & 3.89 & 8.38 & 4.44 \\
\hline $\mathrm{C}_{8}$ & 8.06 & 2.96 & 6.52 & 3.77 \\
\hline $\mathrm{C}_{9}$ & 11.76 & 4.27 & 8.08 & 2.82 \\
\hline $\mathrm{C}_{10}$ & 7.81 & 2.81 & 5.92 & 3.35 \\
\hline $\mathrm{C}_{11}$ & 7.86 & 2.83 & 5.33 & 3.29 \\
\hline $\mathrm{C}_{12+}$ & 27.82 & 10.00 & 40.12 & 24.53 \\
\hline Gas oil ratio (GOR), SCF/STB & - & 859.01 & - & 390.04 \\
\hline Molecular weight (MW) of the residual oil & - & 216 & - & 296 \\
\hline MW of $\mathrm{C}_{12+}$ fraction & - & 508 & - & 532 \\
\hline MW of the reservoir oil & - & 93 & - & 174 \\
\hline Special gravity of $\mathrm{C}_{12+}$ fraction @ 60/60 ${ }^{\circ} \mathrm{F}$ & - & 0.8958 & - & 0.9789 \\
\hline Saturates, wt $\%$ & 71.84 & - & 49.50 & - \\
\hline Aromatics, wt $\%$ & 20.33 & - & 30 & - \\
\hline Resins, wt $\%$ & 6.69 & - & 9.10 & - \\
\hline Asphaltenes, wt $\%$ & 1.14 & - & 11.4 & - \\
\hline Reservoir temperature, ${ }^{\circ} \mathrm{F}$ & - & 270 & - & 205 \\
\hline Reservoir pressure, psi & - & 9500 & - & 4600 \\
\hline Viscosity@20 ${ }^{\circ} \mathrm{C}, \mathrm{cP}$ & - & 5.2 & - & 8.7 \\
\hline
\end{tabular}

Table 2 Dispersants

\begin{tabular}{llc}
\hline Chemical & Basic structure & $\mathrm{MW}, \mathrm{kg} / \mathrm{mol}^{\mathrm{a}}$ \\
\hline DB & Polyisobutylene succinimide & 3900 \\
DF & Polyisobutylene succinic ester & 4260 \\
DP & Nonylphenol-formaldehyde resin modified by polyamines & 8030 \\
DR & Rapeseed oil amide & 560 \\
\hline
\end{tabular}

${ }^{a}$ Average molecular weight was determined by gel permission chromatography (GPC)

\subsection{Experimental apparatus}

The onset of asphaltene precipitation and its stability in dead oil samples were determined with a Motic BA300 POL microscope, an Anton Paar SVM-3000 viscometer, and a Turbiscan MA-2000 when titrating with $n$-alkane under laboratory conditions. The solid detection system
(SDS) and the filtration method were applied under reservoir conditions.

\subsection{Experimental methods}

The concentration of ADs for the dead and live oil samples of A and B was considered being 400 and 350 ppm, respectively. 


\subsubsection{Visual microscopic measurements}

The onset of asphaltene precipitation was determined by titration of crude oil with $n$-heptane, and particles greater than $2 \mu \mathrm{m}$ could be observed by microscopy. Here, $500 \mathrm{~mL}$ of the dead oil in a beaker was stirred with a magnetic stirrer in order to have a homogeneous sample. At each step, a predetermined amount of $n$-heptane $(0.2 \mathrm{~mL})$ was added to $5 \mathrm{~mL}$ of the oil sample and the mixture was agitated vigorously for $5 \mathrm{~min}$ and a small drop of the mixture was observed with the microscope and the formation of asphaltene precipitates was checked. Having determined the precipitation onset for different dispersants, the efficient $\mathrm{AD}$ can be chosen based on the maximum ratio of $n$-heptane to oil.

\subsubsection{Viscometric measurements}

Similar to the previous method, the oil sample was titrated by a precipitant and the viscosity of the mixture was measured at each step. This method was only applied to oils with very low asphaltene content. Therefore, the viscosity measurements were just for oil A.

\subsubsection{Turbidity measurements}

The effect of a dispersant to maintain asphaltenes in a peptized state and to prevent flocculation of asphaltenes was investigated by considering its stability under different conditions. Oil with a low stability is likely to undergo flocculation of asphaltenes when stressed (e.g., the addition of a precipitant). Therefore, this method along with the two previous methods can be helpful for better understanding of the performance of dispersants.

In this technique, photons were sent into the sample. After being scattered by objects in suspension, the photons emerged from the sample and were detected by transmission and backscatter detectors. The change in the transmitted light from the oil sample (including the solvent, asphaltene, precipitant, and dispersant) due to the formation of asphaltene precipitates was measured in a fixed time interval. The less the change in transmitted light, the more the ability of the dispersant to prevent asphaltene precipitation (Fig. 1).

The Turbiscan quantitatively measures how easily the asphaltenes in the mixture of oil and a dispersant, separate upon the addition of $n$-heptane. The test method calculates a separability number $(\%)$.

When the separability number shown by the Turbiscan is greater than 10 , the sample is unstable. For a separability number less than 5, the sample is stable and finally, the sample has medium stability when the measured number is between 5 and 10 . The stability behavior of the mixture can
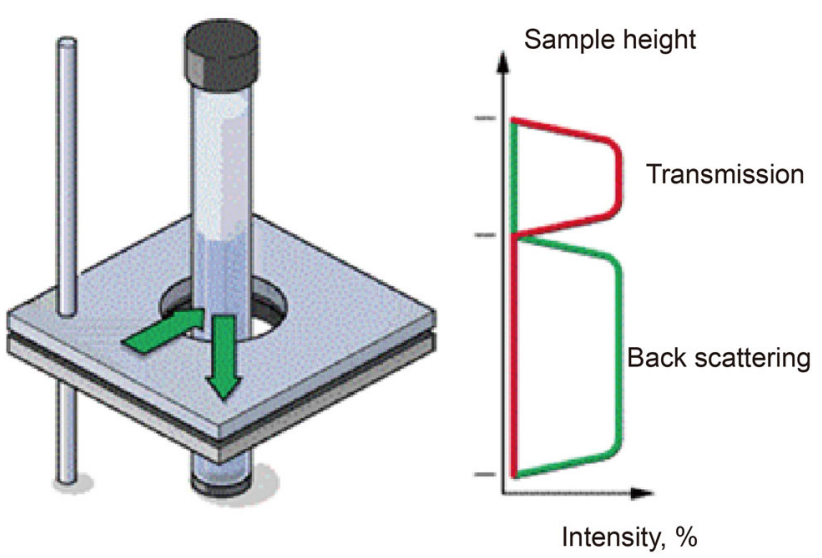

Fig. 1 Schematic of Turbiscan

also be explained by the trends of the transmitted light during the time of measurement (Fig. 2).

If an $\mathrm{AD}$ is effective, it will keep asphaltenes in the solution and there are no asphaltene agglomerate particles. Therefore, the mean transmittance remains constant along the Turbiscan test tube (Fig. 2a). For semi-stability mixtures, the received light varies with time (Fig. 2b). For ineffective ADs, agglomeration occurs and asphaltene particles deposit at the bottom of the test tube. Hence, the mean transmittance increases towards the top of the test tube as the upper part of the test tube becomes less dense (Fig. 2c). In this case, the change in the stability of the fluid depends mostly on the fluid characteristics.

In the first step, the separability number for different volume ratios of oil to $n$-heptane was measured. The aim of this stage is to find out the volume ratio of oil to $n$-heptane under which the mixture is unstable. Immediately after the addition of precipitant, the mixture was shaken for $5 \mathrm{~min}$ and $7 \mathrm{~mL}$ of the prepared sample was placed in the device's test tube. The whole sample was then scanned every minute for at least 15 min (the right axis in Fig. 2). For the next step, a mixture containing oil and a dispersant was prepared; $4 \mathrm{~mL}$ of the mixture were poured into several test tubes and different amounts of $n-\mathrm{C}_{7}$ were added to each of them and rocked for $5 \mathrm{~min}$. Then, $7 \mathrm{~mL}$ of the sample was placed in the Turbiscan cell and its stability was measured.

\subsubsection{SDS procedure}

The live oil was fed into the PVT cell which was placed in a temperature-controlled oven. The pressure and volume of the sample in the cell would be controlled by a variablevolume displacement pump. The mixer inside the PVT cell provided proper mixing of fluids and accelerated the equilibrium condition of the system. Under reservoir temperature and high pressure, more than 10,000 psi, when the sample was in equilibrium, the sample was depressurized 
(a)

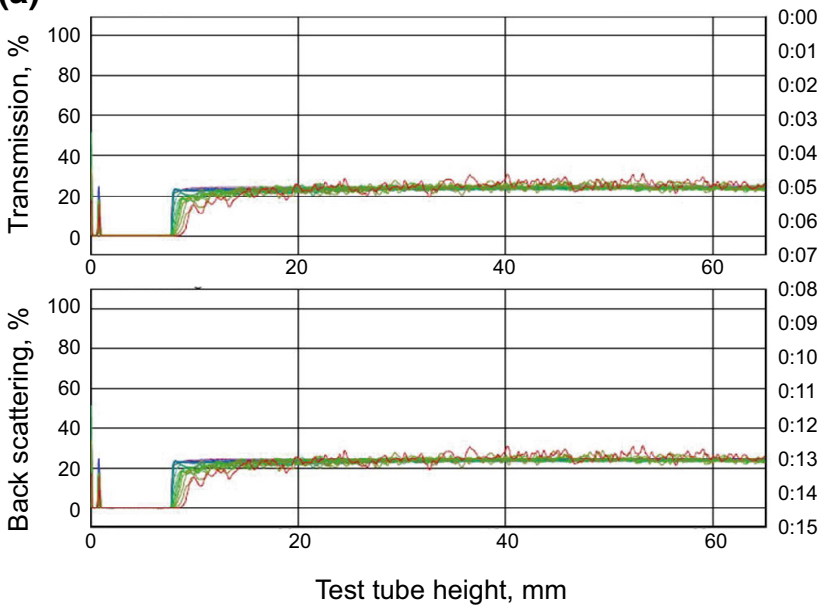

(b)
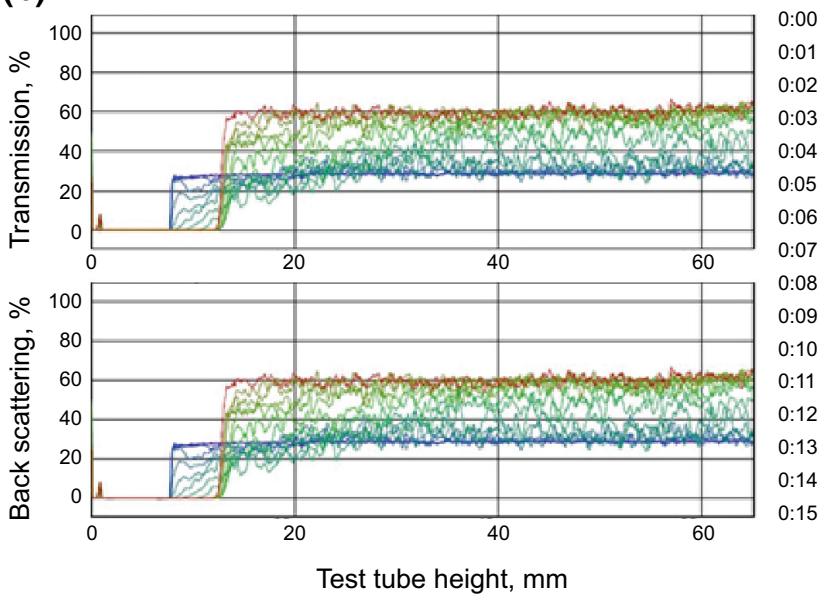

(c)
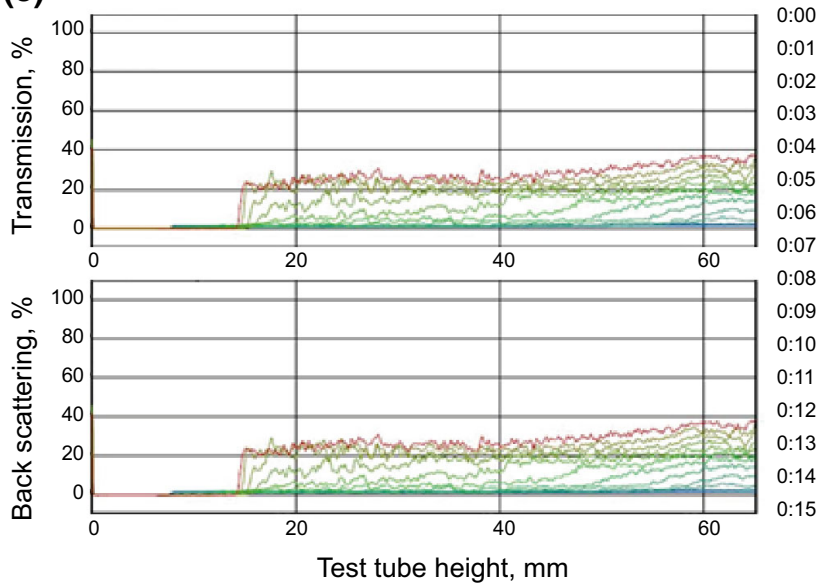

Fig. 2 Received light from stable (a), semi-stable (b), and unstable (c) mixtures (The horizontal axis is the height of the test tube. 0 is the tube bottom and $60 \mathrm{~mm}$ is its upper part)

and the data acquisition system recorded the received power. Due to depressurization, the oil expanded and there would be a reduction in the oil density. Therefore, the optical fibers received more light. At the onset pressure of asphaltene precipitation and below the asphaltene particles absorbed the transmitted light and there was a change in the slope of the graph. However, due to the density reduction it still had a rising trend. The schematic of the SDS setup is shown in Fig. 3.

For evaluation of the selected AD under reservoir conditions, it should be injected into the PVT cell. Since the amount of the $\mathrm{AD}(400 \mathrm{ppm})$ was very low compared to the live oil $(50 \mathrm{~mL})$, therefore one experiment was designed under laboratory conditions to determine the best carrier fluid. With $1 \mathrm{~mL}$ of this fluid, the $\mathrm{AD}$ can be added to the live oil. Before selecting the best carrier fluid, the origin of solid particles should be known. Several tests were conducted to characterize the solid particles, including X-ray diffraction (XRD), X-ray fluorescence (XRF), ash content, IP-143, and saturates, aromatics, resins and asphaltenes (SARA) tests. These analyses can determine the presence of different elements in addition to the amount of asphaltenes in the solids.

In the first set of tests, the amount of asphaltene solids which can be dissolved in different solvents was investigated and the results were compared with dissolution power of xylene. Xylene is very useful to remove organic materials; however, it is a hazardous air pollutant and is known or suspected to cause cancer or other serious health problems. Xylene is also expensive and it is not economic to use large amounts. We tried here to decrease xylene concentration in the carrier fluid. For this purpose, the asphaltene particles were broken into small pieces and then ground with a mortar and pestle and $0.5 \mathrm{~g}$ of asphaltene powders were placed in a test tube. $50 \mathrm{~mL}$ of solvent was added to the powder. The prepared mixture was shaken 


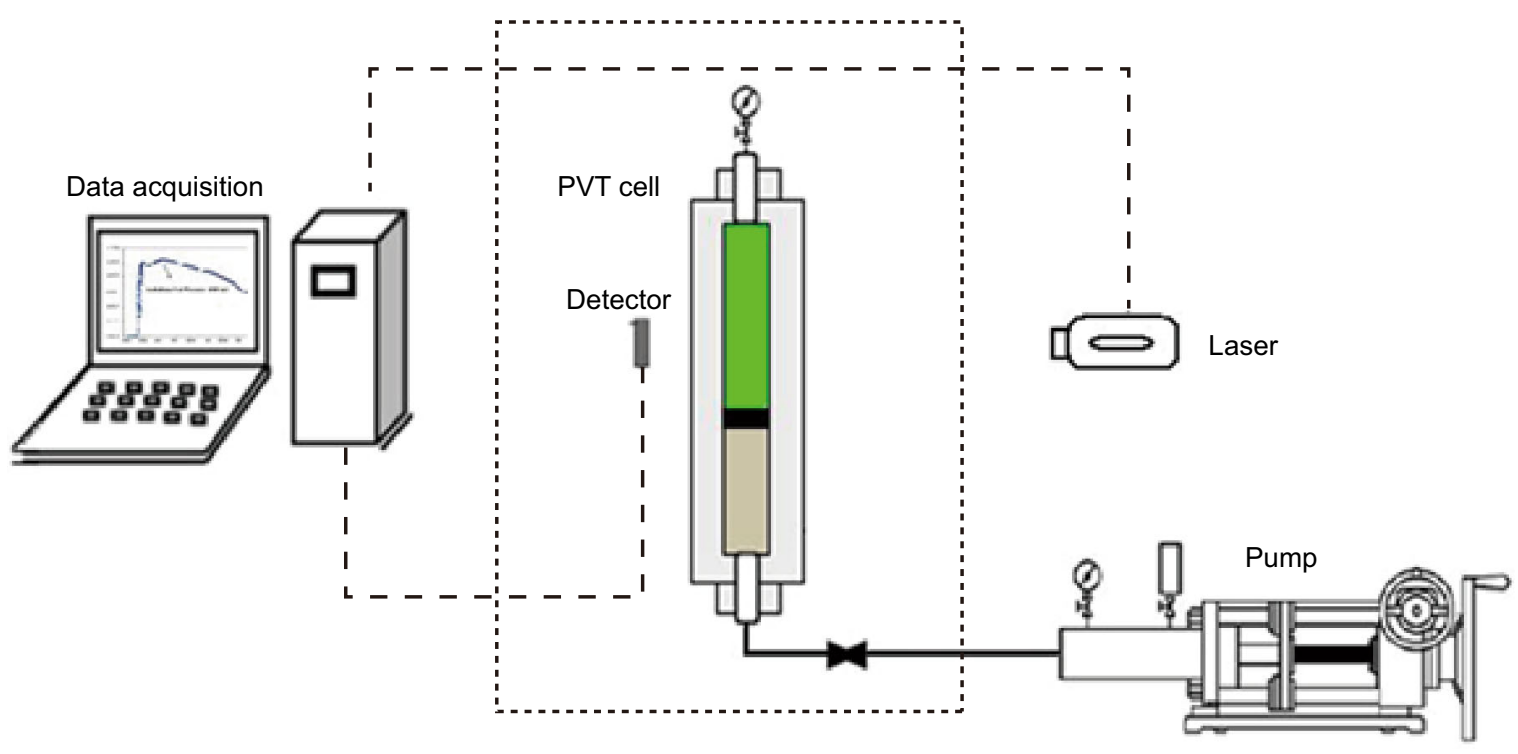

Fig. 3 The schematic of SDS setup

rigorously until the asphaltene dispersed into the solvent. After 15 min the sample was passed through a filter paper. The filter paper was then put in the oven for $2 \mathrm{~h}$ at $220{ }^{\circ} \mathrm{C}$. The weights of the filter paper, before and after the experiment, can determine the amount of asphaltenes which was dissolved into the solvent. We could not perform this method for oil B as it is very dark and heavy. Therefore, all the measurements are for oil A.

\subsubsection{Filtration method}

The sample underwent a similar path as the SDS method; however, at each pressure step, it passed through the stainless steel filter (SWAGLOK, $0.2 \mu \mathrm{m}$ ) and the asphaltene aggregates greater than $0.2 \mu \mathrm{m}$ remained on the filter surface. The maximum allowable differential pressure for this type of filter is 1000 psi. However, in this experiment, we tried to avoid differential pressures higher than 200 psi during sampling (Fig. 4). The change in the asphaltene content of the crude oil could determine the amount of asphaltenes precipitated and deposited in the PVT cell. For evaluating the selected ADs under reservoir conditions, the mixture of the $\mathrm{AD}$ and the carrier fluid was injected into the PVT cell at pressures higher than the onset pressure of asphaltene precipitation. By comparing the graphs of asphaltene weight percent versus pressure, with and without the presence of ADs, one could determine the efficiency of the AD under reservoir conditions. This method was used instead of the SDS method for heavy oils and oils with high asphaltene content. The measurements, here, are for oil B.

\section{Results and discussion}

\subsection{Results of the tests under laboratory conditions}

\subsubsection{Microscopic test}

The onset of asphaltene precipitation measured by titration for different oil/AD systems are shown in Tables 3 and 4. The effect of toluene and xylene on the onset of asphaltene precipitation was also investigated.

Tables 3 and 4 indicate that dispersants DB and DP show better performance than dispersants DF and DR since the precipitation onset of blank oil A changed from 0.43 to a value about 0.6 . For dead oil $\mathrm{B}$, the change in the onset was from 0.63 to 0.72 . Dispersants DB and DP may delay the onset of asphaltene precipitation so that a higher volume ratio of $n$-heptane to oil is required for asphaltene precipitation. In addition, the two solvents, toluene and xylene, did not show significant effect on the onset of asphaltene precipitation. Figures 5 and 6 show the snapshots from samples under the microscope before and after the appearance of onset of asphaltene precipitation upon the addition of $n$-heptane on oil A. It was observed that dispersants with better performance prevent the formation of bigger aggregates, which is in agreement with the purpose of using ADs.

\subsubsection{Viscometer test}

In order to compare the inhibition power of ADs, the best dispersant (DP) and the worst one (DR) were selected from 


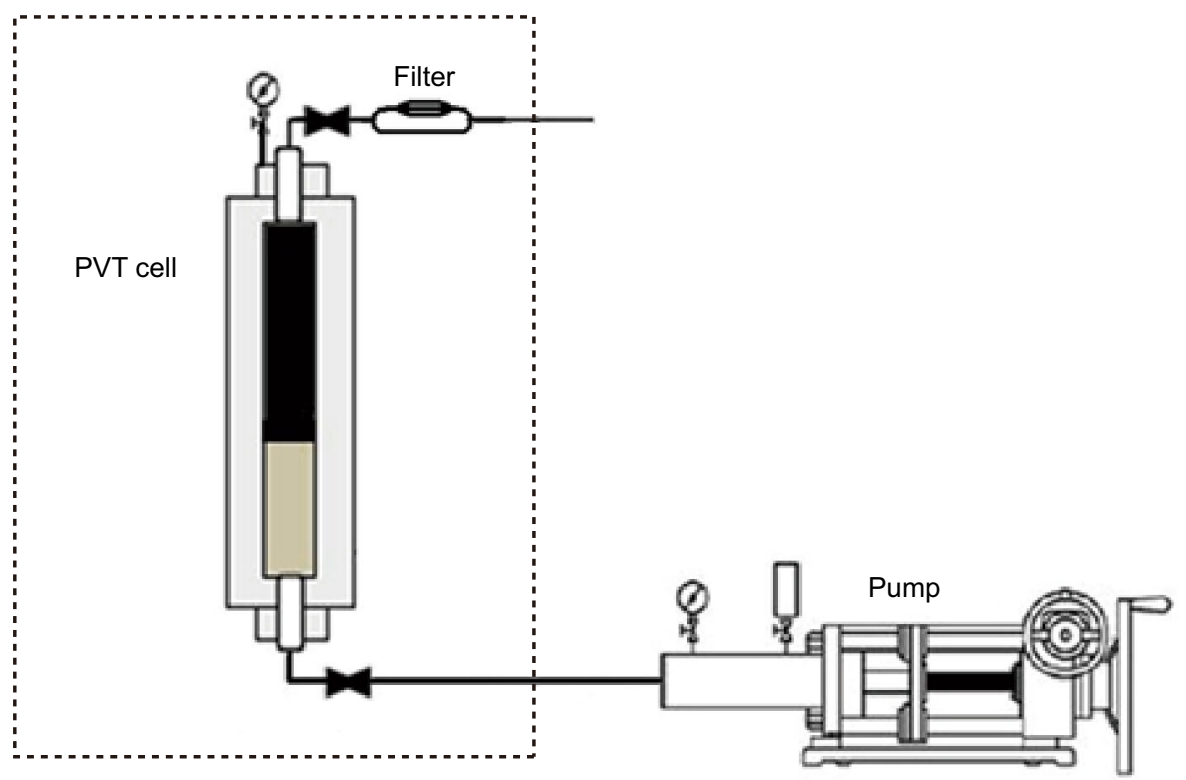

Fig. 4 The schematic of the filtration apparatus

Table 3 Onset of asphaltene precipitation in the presence of dispersants in the dead oil A

\begin{tabular}{llllll}
\hline Sample no. & Oil vol. $V_{\text {oil }}, \mathrm{mL}$ & Dispersant & AD concentration, ppm & $n$-Heptane vol. $V_{n \text {-heptane }}, \mathrm{mL}$ & Onset, $V_{n \text {-heptane }} / V_{\text {oil }}$ \\
\hline 1 & 40 & - & - & 17.0 & 0.43 \\
2 & 40 & DB & 400 & 23.5 & 0.58 \\
3 & 40 & DF & 400 & 20.5 & 0.51 \\
4 & 40 & DP & 400 & 24.0 & 0.60 \\
5 & 40 & DR & 400 & 17.5 & 0.44 \\
6 & 40 & Toluene $(1 \mathrm{~mL})$ & - & 17.8 & 0.45 \\
7 & 40 & Xylene $(1 \mathrm{~mL})$ & - & 18.3 & 0.46 \\
\hline
\end{tabular}

Table 4 Onset of asphaltene precipitation in the presence of dispersants in the dead oil B

\begin{tabular}{llllll}
\hline Sample no. & Oil vol. $V_{\text {oil }}, \mathrm{mL}$ & Dispersant & AD concentration, $\mathrm{ppm}$ & $n$-Heptane vol. $V_{n \text {-heptane, }} \mathrm{mL}$ & Onset, $V_{n \text {-heptane }} / V_{\text {oil }}$ \\
\hline 8 & 40 & - & - & 25.2 & 0.63 \\
9 & 40 & DB & 350 & 28.7 & 0.72 \\
10 & 40 & DF & 350 & 25.9 & 0.65 \\
11 & 40 & DP & 350 & 28.0 & 0.70 \\
12 & 40 & DR & 350 & 25.2 & 0.63 \\
13 & 40 & Toluene $(1 \mathrm{~mL})$ & - & 25.7 & 0.64 \\
14 & 40 & Xylene $(1 \mathrm{~mL})$ & - & 26.0 & 0.65 \\
\hline
\end{tabular}

experimental results obtained with previous methods. Figure 7 shows the changes in viscosity due to the addition of $n$-heptane to different samples. According to Fig. 7, the onset of precipitation can be detected by the change in the slope of the viscosity graph. Table 5 shows that the onset of asphaltene precipitation for the blank oil and the mixture of oil and DR were almost equal. Dispersant DP had better performance on delaying asphaltene onset. The results 


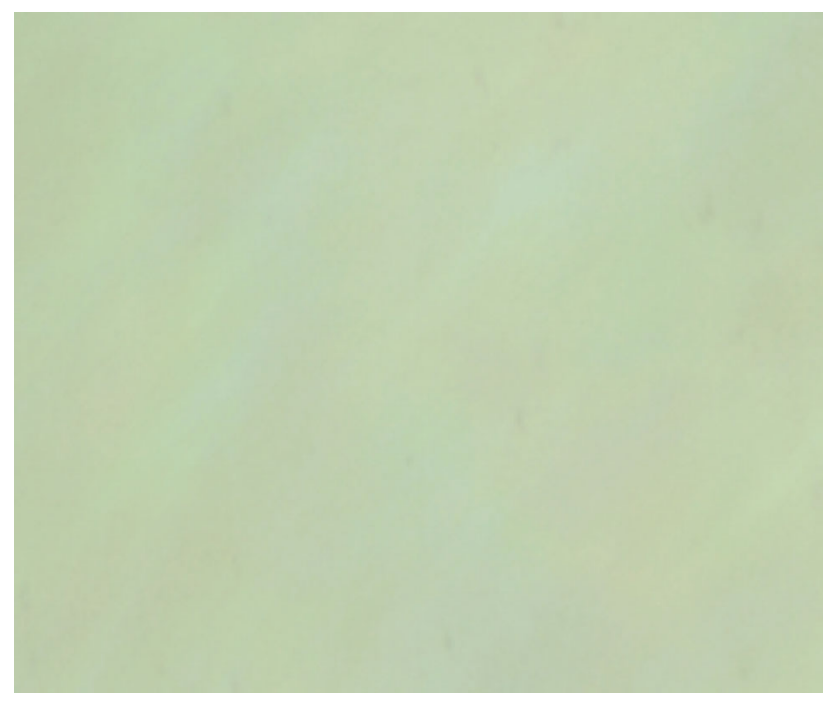

Fig. 5 Before the formation of asphaltene precipitation (dead oil A)

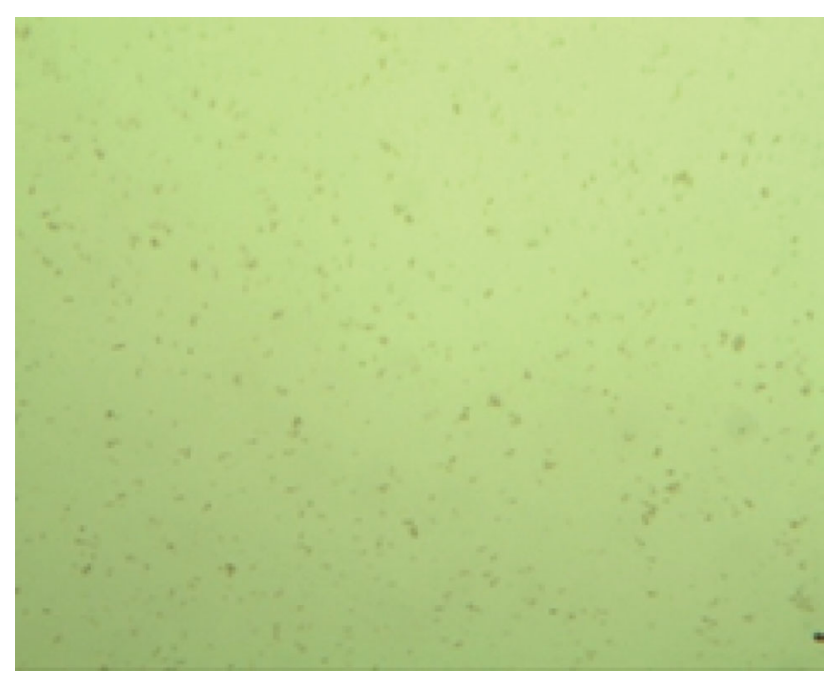

Fig. 6 Onset of asphaltene precipitation (dead oil A)

obtained here are in good agreement with the results of the two previous methods for oil A.

Before the onset of asphaltene precipitation, the addition of $n$-heptane dilutes the mixture that is why there is a decreasing trend in the slope of the graph. However, at the onset point, the viscosity increases owing to the formation of asphaltene aggregates. The effect of precipitating asphaltenes may not be apparent until well beyond the onset of asphaltene precipitation due to its low concentration. The change in the slope of graphs is not as sharp as it was reported by Mousavi-Dehghani et al. (2004). Any further increase in the volume of $n$-heptane can dilute the mixture and it will cover the effect of precipitated asphaltenes. The onset values from viscometric and microscopic methods are a little bit different from each

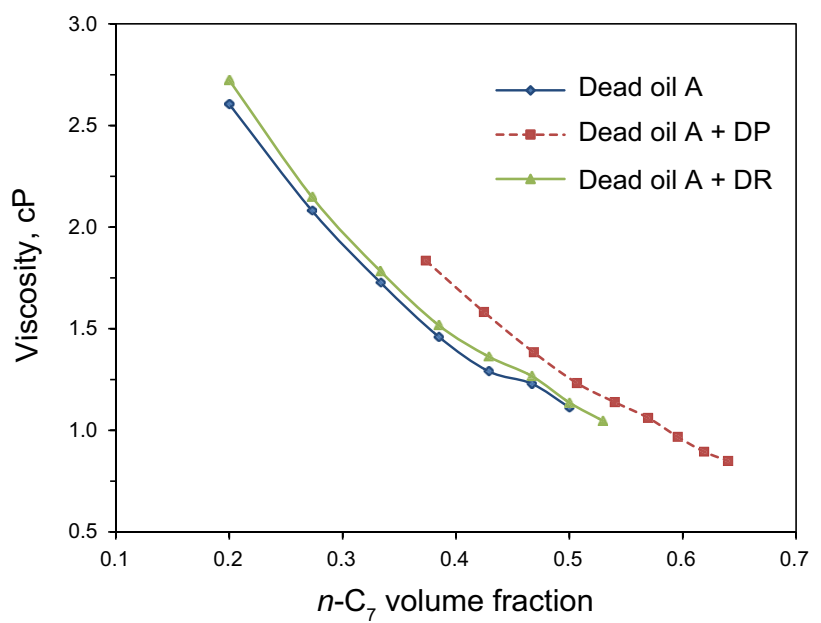

Fig. 7 Viscosity changes based on the addition of $n$ - $\mathrm{C}_{7}$ to dead oil A, dead oil A + DP (400 ppm), and dead oil A + DR (400 ppm)

other and such results were expected since the methods are based on distinct fundamentals (Mansur et al. 2009).

\subsubsection{Turbidity test}

Table 6 shows the ratio of $n$-heptane to oil which leads to the formation of unstable mixtures for both dead oils A and $B$. These ratios can be considered as the reference ratios for the evaluation of dispersants efficiency.

According to Table 7, dispersants DB, DF, and DP are promising chemicals with more positive effect on the stability of asphaltene in both dead oils $\mathrm{A}$ and $\mathrm{B}$. It can also be observed that the dispersant DR is inefficient in both oil samples.

\subsection{Results of the tests under reservoir conditions}

The inhibition power of the four dispersants under laboratory conditions is as follows: $\mathrm{DP} \approx \mathrm{DB}>\mathrm{DF}>\mathrm{DR}$. In contrast to dispersants DF and DR, it seems that ADs with nonylphenol-formaldehyde resin modified by polyamines (DP) and polyisobutylene succinimide (DB) bases show higher efficiency on these oil samples. The main focus under reservoir conditions is on dispersants DP and DB to select the best one for field applications.

\subsubsection{SDS}

The analyses of solid particles are presented in Tables 8 and 9. The results show that a very small proportion of solid particles $(0.3 \%)$ were made up of inorganic material and the rest were organic. As such, elemental analyses are not required, as they are not important in comparison with organic components $(99.7 \%)$. The SARA analysis 
Table 5 Onset of asphaltene precipitation with and without a dispersant, determined by viscosity measurement

Table 6 Asphaltene stability at different $n$-heptane/oil ratios

\begin{tabular}{llcl}
\hline Sample & Oil vol. $V_{\text {oil }}, \mathrm{mL}$ & Dispersant concentration, ppm & Onset, $V_{n \text {-heptane }} / V_{\text {oil }}$ \\
\hline Dead oil A & 1 & 0 & 0.45 \\
Dead oil A + DP & 1 & 400 & 0.56 \\
Dead oil A + DR & 1 & 400 & 0.46 \\
\hline
\end{tabular}

\begin{tabular}{lllll}
\hline Oil & Oil vol., $\mathrm{mL}$ & $n$-heptane vol., $\mathrm{mL}$ & Separability number & Stability \\
\hline Dead oil A & 1 & 10 & 2.2 & High \\
& 1 & 20 & 3.7 & High \\
& 1 & 40 & 11.2 & Low \\
Dead oil B & 1 & 10 & 0 & High \\
& 1 & 20 & 1.3 & High \\
& 1 & 30 & 3.7 & High \\
& 1 & 50 & 12.7 & Low \\
\hline
\end{tabular}

Table 7 The effect of dispersants on the asphaltene stability

\begin{tabular}{|c|c|c|c|c|c|c|}
\hline Sample & Dispersant & Oil vol., mL & $n$-heptane vol., $\mathrm{mL}$ & Dispersant concentration, ppm & Separability number & Stability \\
\hline \multirow[t]{5}{*}{ Dead oil A } & - & 1 & 40 & - & 11.2 & Low \\
\hline & DB & 1 & 40 & 400 & 0.4 & High \\
\hline & DF & 1 & 40 & 400 & 0.5 & High \\
\hline & DP & 1 & 40 & 400 & 0.3 & High \\
\hline & DR & 1 & 40 & 400 & 11.0 & Low \\
\hline \multirow[t]{5}{*}{ Dead oil B } & - & 1 & 50 & - & 12.7 & Low \\
\hline & DB & 1 & 50 & 350 & 0.1 & High \\
\hline & $\mathrm{DF}$ & 1 & 50 & 350 & 1.7 & High \\
\hline & DP & 1 & 50 & 350 & 0 & High \\
\hline & DR & 1 & 50 & 350 & 12.2 & Low \\
\hline
\end{tabular}

Table 8 Ash content of the solid particles

\begin{tabular}{ll}
\hline Procedure & Ash content, wt\% \\
\hline ASTM D-482 & 0.3 \\
\hline
\end{tabular}

(Table 9) indicates that the solids consisted mainly of asphaltenes.

The dissolution power of different solvents defined as the wt\% of solid asphaltene particles dissolved in the solvent was measured and presented in Fig. 8. Solvents which show similar effect to xylene for dissolving solids can be considered as carrier fluids. The results show that apart from the pure xylene and toluene, a mixture of xylene and kerosene with volume ratios of 80:20 and 60:40 can give higher efficiency compared to other solvents. Here, a mixture of xylene and kerosene with a ratio of 80:20 was selected as the carrier fluid.
Table 9 SARA analysis of solid particles

\begin{tabular}{llll}
\hline Asphaltenes, $\%$ & Resins, \% & Aromatics, \% & Saturates, \% \\
\hline 54.0 & 6.6 & 12.9 & 26.5 \\
\hline
\end{tabular}

For the first step, the onset pressure of asphaltene precipitation for the live oil was obtained. This step is necessary for investigating the effectiveness of ADs. Since the amount of live oil was known, the prepared mixture of carrier fluid and dispersant should be such that the final mixture has the desired concentration of the AD. Here, $1 \mathrm{~mL}$ of the solvent accompanied by the selected AD was injected into the PVT cell containing $50 \mathrm{~mL}$ of live oil A. In Fig. 9, the onset of asphaltene precipitation of the live oil was determined, which is about 4300 psi. The effect of ADs on the onset pressure can be observed in Fig. 9. The figure clearly shows that dispersants DP and DB had 


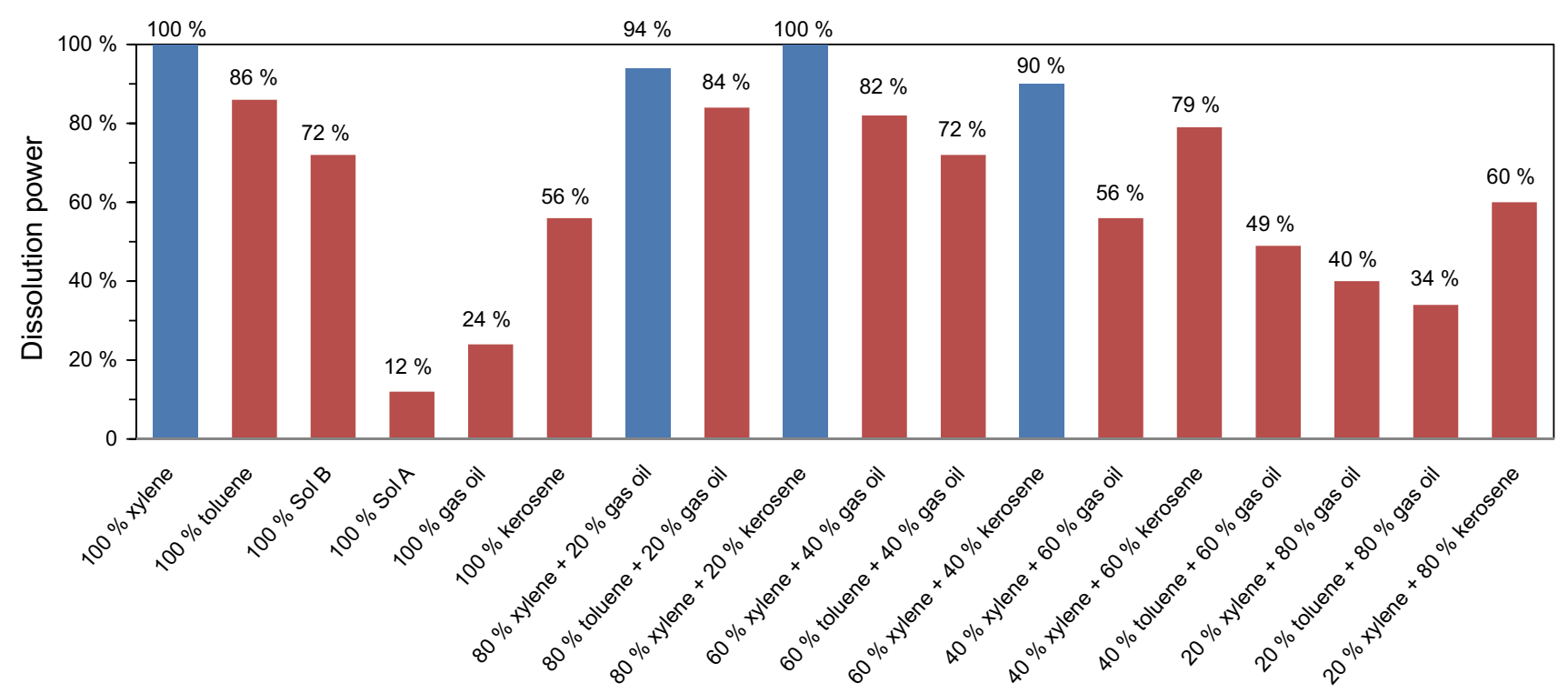

Fig. 8 The dissolution power of different solvents

altered the asphaltene onset pressure (AOP) and decreased it to 3600 and $4000 \mathrm{psi}$, respectively. Figure 9 also demonstrates the dispersant DP prevented asphaltene aggregation and kept it in the solution. Below the onset of asphaltene precipitation and above the bubble point, the pressure reduction led to an increase in the size of aggregates; however, the presence of dispersant in the solution inhibited the growth of aggregated asphaltenes.

\subsubsection{Filtration}

According to the literature, due to depressurization above the bubble point, the screening effect on the asphaltene nanoaggregates decreases and as a result the

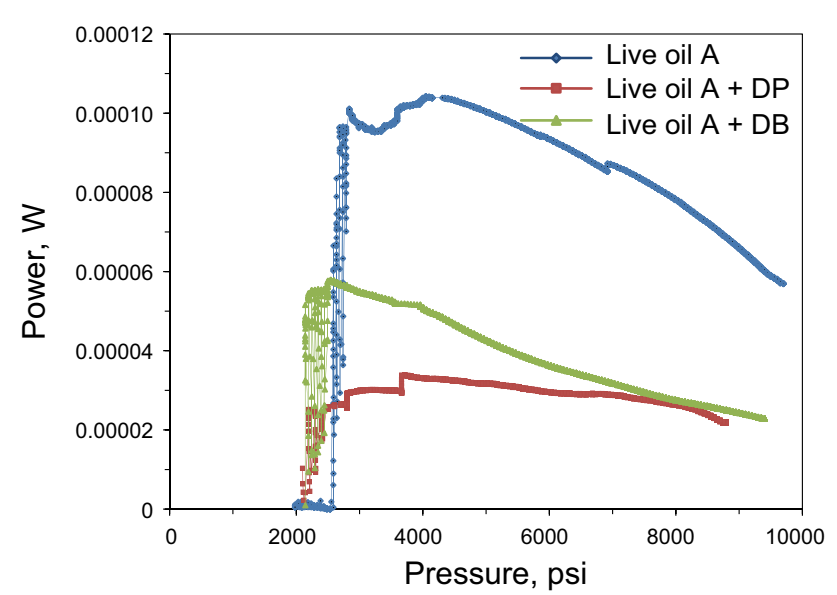

Fig. 9 Asphaltene precipitation onset for live oil A, live oil + DP (400 ppm), live oil + DB (400 ppm) interactions between them become greater; therefore precipitation occurs. Below the bubble point pressure, the solubility of asphaltene increases as the light fraction of oil separated from oil (Buenrostro-Gonzalez et al. 2004; Shokrlu et al. 2011). Figure 10 shows that the amount of asphaltenes precipitated in the presence of DP decreased to over $30 \%$ of its initial value. The graph also shows that the addition of chemicals did not change the bubble point of the crude oil because of the addition of very small amount of chemicals in comparison to the live oil. The accuracy of this method depends considerably on the asphaltene content of the crude oil. For light oils (i.e., low asphaltene content) it is almost impossible

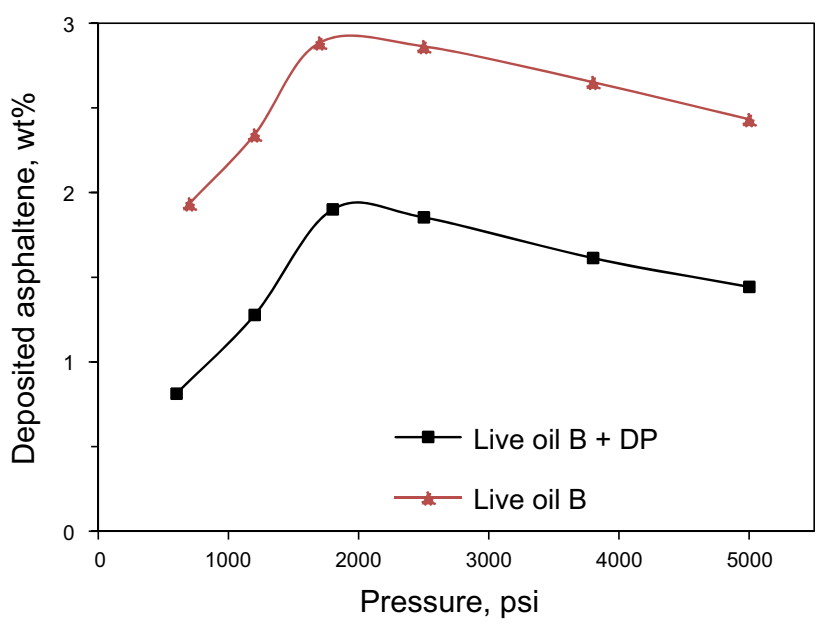

Fig. 10 Change in asphaltenes (wt \%) during pressure depletion for live B and live oil B + DP (350 ppm) 
Table 10 Overview of experimental results

\begin{tabular}{|c|c|c|c|c|c|c|c|c|c|}
\hline Sample & Test condition & Oil & Experiment & Method of AD selection & $\mathrm{DB}$ & DF & DP & $\mathrm{R}$ & Best chemical \\
\hline \multirow[t]{4}{*}{ Oil A } & \multirow[t]{3}{*}{ Atmospheric } & Dead & Microscopy & Onset point by high ratio of $n$ - $\mathrm{C}_{7} /$ oil & $\sqrt{ }$ & $\sqrt{ }$ & $\sqrt{ }$ & $\sqrt{ }^{\mathrm{a}}$ & $\mathrm{DP}, \mathrm{DB}$ \\
\hline & & Dead & Turbiscan & Low separability number $(<5.0)$ & $\sqrt{ }$ & $\sqrt{ }$ & $\sqrt{ }$ & $\sqrt{ }$ & $\mathrm{DP}, \mathrm{DB}, \mathrm{DF}$ \\
\hline & & Dead & Viscometer & Onset point by high ratio of $n$ - $\mathrm{C}_{7} /$ oil & - & - & $\sqrt{ }$ & $\sqrt{ }$ & DP \\
\hline & Reservoir & Live & SDS & Low onset pressure & $\sqrt{ }$ & - & $\sqrt{ }$ & - & DP \\
\hline \multirow[t]{3}{*}{ Oil B } & \multirow[t]{2}{*}{ Atmospheric } & Dead & Microscopy & Onset point by high ratio of $n$ - $\mathrm{C}_{7} /$ oil & $\sqrt{ }$ & $\sqrt{ }$ & $\sqrt{ }$ & $\sqrt{ }$ & DB, DP \\
\hline & & Dead & Turbiscan & Low separability number $(<5.0)$ & $\sqrt{ }$ & $\sqrt{ }$ & $\sqrt{ }$ & $\sqrt{ }$ & $\mathrm{DP}, \mathrm{DB}, \mathrm{DF}$ \\
\hline & Reservoir & Live & Filtration & Low asphaltene content & - & - & $\sqrt{ }$ & - & DP \\
\hline
\end{tabular}

a Test was done

to follow the effect of thermodynamic changes on the asphaltene precipitation behavior using the filtration method.

The results obtained here demonstrate that in order to select the best asphaltene dispersant for injection into wells, it is compulsory to screen the available chemicals under laboratory conditions to minimize cost and time and then choose the high efficient ones for tests under reservoir conditions. An overview of the experiments is presented in Table 10.

These experiments are valuable as they provide reliable estimation of the results that more likely happen in the field. Based on the acquired results, the injection of the selected dispersant (DP) can properly disperse the aggregating asphaltenes.

\section{Conclusions}

In this study, four asphaltene dispersants, polyisobutylene succinimide (DB), polyisobutylene succinic ester (DF), nonylphenol-formaldehyde resin modified by polyamines (DP), and rapeseed oil amide (DR) were evaluated under laboratory and reservoir conditions. In order to obtain reliable results, full analyses of reservoir fluids and solid asphaltene particles were done. The conditions at which the asphaltene is precipitated out of the solution, such as the addition of precipitant and changing the pressure were conducted on the oil samples with and without ADs. The following results were obtained:

(1) The solid particles contained nearly all organic material and they were mainly of asphaltenes. A mixture of $20 \%$ kerosene and $80 \%$ xylene could completely dissolve the asphaltene solids.

(2) Under laboratory conditions, dispersant DR, fatty oil amide based on rapeseed oil, had the lowest performance among the four different ADs on oil A and oil B.
(3) The onsets of asphaltene precipitation obtained under laboratory conditions using viscometry and microscopy methods are virtually equal. The onset of asphaltene precipitation and its stability was investigated by an optical microscope, a viscometer, and a Turbiscan under laboratory conditions. The SDS setup and filtration method were also applied under reservoir conditions to find the effect of dispersants on the onset pressure of asphaltene precipitation. Among different dispersants, the dispersant DP, based on nonylphenol-formaldehyde resin modified by polyamines, proved to have the best performance under laboratory and reservoir conditions as it moved the onset pressure from 4300 to 3600 psi. Tests on the selected dispersants under reservoir conditions show that in contrast to dispersant DB, dispersant DP in the oil phase inhibited the formation of higher aggregates below the onset pressure of asphaltene precipitation when the pressure decreased. This is exactly what the ADs are expected to do.

Open Access This article is distributed under the terms of the Creative Commons Attribution 4.0 International License (http://crea tivecommons.org/licenses/by/4.0/), which permits unrestricted use, distribution, and reproduction in any medium, provided you give appropriate credit to the original author(s) and the source, provide a link to the Creative Commons license, and indicate if changes were made.

\section{References}

Barcenas M, Orea P, Buenrostro-Gonzalez E, et al. Study of medium effect on asphaltene agglomeration inhibitor efficiency. Energy Fuels. 2008;22(3):1917-22. doi:10.1021/ef700773m.

Borchardt JK. Chemicals used in oil-field operations. In: Oil-field chemistry, ACS Symposium Series. Washington: ACS; 1989. 396:3-54.

Bouts MN, Wiersma RJ, Muijs HM, Samuel AJ. An evaluation of new asphaltene inhibitors: laboratory study and field testing. J Pet Technol. 1995;47(9):782-7. 
Buenrostro-Gonzalez E, Lira-Galeana C, Gil-Villegas A, Wu J. Asphaltene precipitation in crude oils: theory and experiments. AIChE J. 2004;50(10):2552-70. doi:10.1002/aic.10243.

Cosultchi A, Garciafigueroa E, Carcia-Borquez A, et al. Petroleum solid adherence on tubing surface. Fuel. 2001;80(13):1963-8.

Ferrara M. Hydrocarbon oil-aqueous fuel and additive compositions. WO Patent 1995:637.

Hirscberg LNJ, de Jong BA, Schipper BA, Meijer JG. Influence of temperature and pressure on asphaltene flocculation. SPE J. 1984;24(3):283-93. doi:10.2118/11202-PA.

Junior LCR, Ferreira MS, Ramos ACS. Inhibition of asphaltene precipitation in Brazilian crude oils using new oil soluble amphiphiles. J Pet Sci Eng. 2006;51(1-2):26-36. doi:10.1016/j. petrol.2005.11.006.

Kawanaka S, Park SJ, Mansoori GA. Organic deposition from reservoir fluids: a thermodynamic predictive technique. SPE Reserv Eng. 1991;6(2):185-92. doi:10.2118/17376-PA.

Leontaritis KJ. Offshore asphaltene and wax deposition: problems/solutions. World Oil. 1996;217(5):57-63.

Manek MB. Asphaltene dispersants as demulsification aids. In: SPE international symposium on oilfield chemistry, 14-17 February, San Antonio; 1995. doi:10.2118/28972-MS.

Mansoori GA. Modeling of asphaltene and other heavy organic depositions. J Pet Sci Eng. 1997;17(1-2):101-11. doi:10.1016/ S0920-4105(96)00059-9.

Mansoori GA. Remediation of asphaltene and other heavy organic deposits in oil wells and in pipelines. ELMI Sarlar J Reserv Pet Eng. 2010;SOCAR:12-23.

Mansur CRE, Guimaraes ARS, Gonzalez G, Lucas EF. Determination of the onset of asphaltene precipitation by visible ultraviolet spectrometry and spectrofluorimetry. J Anal Lett. 2009;42(16):2648-64.

Marques LCC, Gonzalez G, Monteiro JB. A chemical approach to prevent asphaltenes flocculation in light crude oils: state of the art. In: SPE annual technical conference and exhibition, 26-29 September, Houston; 2004. doi:10.2118/91019-MS.

Miri R, Zendehboudi S, Kord Sh, et al. Experimental and numerical modeling study of gravity drainage considering asphaltene deposition. Ind Eng Chem Res. 2014;53(28):11512-26. doi:10. 1021/ie404424p.

Mousavi-Dehghani SA, Riazi MR, Vafaie-Sefti M, Mansoori GA. An analysis of methods for determination of onsets of asphaltene phase separations. J Pet Sci Eng. 2004;42:145-56. doi:10.1016/j. petrol.2003.12.007.

Oschmann HJ. New methods for the selection of asphaltene inhibitors in the field. Special Publication, Royal Society of Chemistry. 2002;280:254-63.

Shokrlu YH, Kharrat R, Ghazanfaria MH, Saraji S. Modified screening criteria of potential asphaltene precipitation in oil reservoirs. Pet Sci Technol. 2011;29(13):1407-18. doi:10.1080/ 10916460903567582.

Smith DF, Klein GC, Yen AT, et al. Crude oil polar chemical composition derived from FT-ICR mass spectrometry accounts for asphaltene inhibitor specificity. Energy Fuels. 2008;22(5): 3112-7. doi:10.1021/ef800036a.

Speight JG, Wernick DL, Gould KA, et al. Molecular weight and association of asphaltenes: a critical review. Oil Gas Sci Technol: Rev. IFP. 1985;40(1):51-61. doi:10.2516/ogst:1985004.

Takhar S. A fast and effective chemical screening technique for identifying asphaltene inhibitors for field deployment. In: Proceedings of the second international conference on fluid and thermal energy conversion 1997; 83-90.

Thawer R, Nicoll DCA, Dick G. Asphaltene deposition in production facilities. SPE Prod Eng. 1989;5(4):475-80. doi:10.2118/18473PA.

Turta A, Najman J, Fisher D, Singhal A. Viscometric determination of the onset of asphaltene flocculation. In: Annual technical meeting, 8-11, June, Calgary; 1997. doi:10.2118/97-81-MS.

Zendehboudi S, Ahmadi MA, Mohammadzadeh OR, et al. Thermodynamic investigation of asphaltene precipitation during primary oil production: laboratory and smart technique. Ind Eng Chem Res. 2013;52:6009-31. doi:10.1021/ie301949c.

Zendehboudi S, Shafiei A, Bahadori A, et al. Asphaltene precipitation and deposition in oil reservoirs-technical aspects, experimental and hybrid neural network predictive tools. Chem Eng Res Des. 2014;92(5):857-75. doi:10.1016/j.cherd.2013.08.001. 